\title{
Hubungan antara Kelebihan Berat Badan dengan Kekuatan Tulang Perempuan Lansia
}

\author{
Denina Kusumaningayu Puspitarini ${ }^{1}$, Basuki Supartono ${ }^{2 *}$, Yuli Suciati ${ }^{3}$ \\ Program Studi Sarjana Kedokteran, Fakultas Kedokteran Universitas Pembangunan Nasional \\ Veteran Jakarta ${ }^{1}$ \\ Departemen Ortopedi di Fakultas Kedokteran Universitas Pembangunan Nasional Veteran \\ Jakarta ${ }^{2}$ \\ Departemen Anatomi di Fakultas Kedokteran Universitas Pembangunan Nasional Veteran \\ Jakarta ${ }^{3}$ \\ JI. RS Fatmawati, Pondok Labu, Jakarta Selatan 12450, Telp. (021) 7656971 \\ *e-mail: drbasuki@gmail.com
}

\begin{abstract}
Abstrak
Osteoporosis merupakan salah satu penyakit degeneratif yang banyak terjadi pada perempuan lansia. Terdapat beberapa faktor risiko diantaranya adalah usia dan indeks massa tubuh. Berat badan berlebih pada lansia dapat mempengaruhi kekuatan tulang yang mungkin memberikan efek protektif, sehingga penelitian ini bertujuan untuk mengetahui hubungan antara kelebihan berat badan (overweight dan obesitas) dengan kekuatan tulang perempuan lansia. Penelitian ini merupakan observasional analitik dengan desain potong lintang dan pendekatan korelasi. Dengan teknik acak sederhana, sejumlah 104 perempuan lansia dihitung indeks massa tubuh menggunakan timbangan dan staturameter serta diukur kekuatan tulangnya menggunakan BMD (Bone Mineral Densitometry) jinjing sebagai deteksi dini osteoporosis, yang dilakukan di Rumah Sakit Umum Al-Fauzan, Kota Jakarta Timur, pada bulan Oktober 2019. Hasil penelitian didapatkan subjek overweight sebanyak 77 orang (74\%) dan obesitas 27 orang (26\%). Dari subjek overweight terdapat 68 orang $(88,3 \%)$ menderita osteoporosis, dan 9 orang $(11,7 \%)$ menderita osteopenia. Dari subjek obesitas 22 orang $(81,5 \%)$ menderita osteoporosis dan 5 orang (18,5\%) menderita osteopenia. Berdasarkan uji Chi-Square dari kedua varibel, dapat disimpulkan bahwa penelitian ini tidak menunjukkan hubungan yang bermakna antara kelebihan berat badan dengan kekuatan tulang perempuan lansia, $p=0.512$ (derajat kemaknaan $<0.05$ ). Kelebihan berat badan seperti overweight ataupun obesitas mungkin tidak dianggap sebagai faktor pelindung terhadap osteoporosis pada perempuan lanjut usia.
\end{abstract}

Kata Kunci: Kelebihan berat badan, kekuatan tulang, perempuan lansia.

\section{Correlation Between Excess Body Weight and Bone Strength in Elderly Women}

\begin{abstract}
Osteoporosis is a degenerative disease that occurs in many elderly women. There are several risk faktors, including age and body mass index. Being overweight in the elderly can affect bone strength which may have a protective effect, so this study aims to determine the relationship between being excess body weight (overweight and obese) and bone strength in elderly women. This research is an observational analytic with a cross-sectional design. A total of 104 elderly women was calculated on their body mass index using scales and a stature meter, afterward, their bone strength was measured using a portable BMD (Bone Mineral Densitometry) as early detection of osteoporosis, which was carried out at Al-Fauzan General Hospital, East Jakarta City, October 2019. The results showed that 77
\end{abstract}


Hubungan antara Kelebihan Berat Badan dengan Kekuatan Tulang Perempuan Lansia

Denina Kusumaningayu Puspitarini, Basuki Supartono, Yuli Suciati

subjects were overweight (74\%) and obese 27 people (26\%). There were 68 people (88.3\%) suffering from osteoporosis, and 9 people (11.7\%) suffering from osteopenia in the overweight subjects. While the obese subjects, 22 (81.5\%) had osteoporosis, and 5 (18.5\%) had osteopenia. Based on the ChiSquare test of the two variables, it can be concluded that this study did not show a significant relationship between excess body weight and bone strength in elderly women, $p=0.512$ (degree of significance $<0.05)$. Being overweight or obese may not be considered a protective faktor against osteoporosis in elderly women.

Keywords: Overweight, bone strength, elderly women.

\section{PENDAHULUAN}

Osteoporosis merupakan salah satu penyakit degeneratif dan banyak terjadi pada perempuan lansia yang dapat mengarah pada mortalitas dan morbiditas (Kementrian Kesehatan Republik Indonesia, 2015). Dari hasil proyeksi penduduk di Indonesia, terdapat $10 \%$ penduduk akan berusia 60 tahun ke atas dan rata-rata akan mengalami satu patah tulang atau kecacatan permanen, bahkan kematian (Kementrian Kesehatan Republik Indonesia, 2015; Greco EA, 2011).

Faktor risiko osteoporosis diantaranya adalah usia dan indeks massa tubuh yang berlebih. Pada perempuan pasca menopause terjadi penurunan kadar hormon estrogen dan peningkatan aktivitas sel osteoklas yang berdampak pada kekuatan tulang (Brunetti et al, 2014). Massa tubuh berlebih karena penimbunan lemak, akan bertambah dengan penuaan (Shapses \& Sukumar, 2012). Menurut morris, kelebihan berat badan justru bersifat protektif artinya meningkatkan kekuatan tulang pada perempuan lansia (MorrisNaumann FL \& Wark JD, 2015). Hasil studi Greco menjelaskan bahwa keropos tulang lebih banyak dialami individu dengan berat badan normal atau rendah dibandingkan individu dengan kelebihan berat badan atau obseitas (Greco et al, 2010).

Bertolak belakang dengan hal tersebut, peningkatan berat badan (obesitas) menyebabkan sekresi sitokin proinflamasi dan mengurangi kepadatan mineral tulang (Susan, et al., 2018). Studi Cao (J Cao, 2011) juga menyatakan bahwa obesitas merugikan kekuatan tulang meskipun berpotensi efek positif dari mekanik yang diberikan oleh peningkatan berat badan dengan tulang. Hasil studi yang masih kontroversi, dapat mempengaruhi kualitas hidup lansia di masa mendatang. Maka dari itu, tujuan penelitian ini untuk mengetahui hubungan antara kelebihan berat badan dengan kekuatan tulang perempuan lansia. 


\section{BAHAN DAN METODE}

Tabel 1. Proporsi Penelitian

\begin{tabular}{cccc}
\hline Variabel & P1 & P2 & N \\
\hline Body Mass Index dengan Kepadatan Tulang & 0.2 & 0.5 & $\mathbf{5 2}$
\end{tabular}

Sumber: (Fitria, 2016)

$=(\mathrm{n} \times 2)+10 \%$

$=52 \times 2+10 \%=104$ responden

Desain penelitian observasional analitik dengan metode potong lintang. Sampel mengunakan metode probability sampling dengan teknik simple random sampling, mencakup 104 perempuan lansia dari populasi pasien berusia 60 tahun atau lebih di Rumah Sakit Umum Al- Fauzan. Sampel memenuhi kriteria inklusi, yaitu perempuan berusia $\geq 60$ tahun dengan berat badan berlebih (overweight dan obesitas) dan kriteria eksklusi yaitu riwayat penyakit yang dapat meningkatan risiko osteoporosis seperti Diabetes, keganasan/tumor, gangguan tiroid, hepar dan ginjal, riwayat infeksi tulang dan penggunaan obat steroid jangka panjang.

Peneliti menggunakan data primer yang diperoleh dari wawancara dan pengukuran indeks massa tubuh dengan berat badan menggunakan timbangan injak digital, serta tinggi badan dengan staturemeter; kemudian dilanjutkan mengukur kepadatan tulang.
Instrumen yang digunakan pada penelitian ini adalah Portabel Ultrasound Bone Densitometer Sonost 3000. Wawancara menggunakan kuesioner Osteoporosis Risk Check 2017 untuk mengetahui responden yang sesuai dengan kriteria. Kemudian hasil data akan dianalisis secara univariat dan bivariat menggunakan uji Chi-Square dengan interval kepercayaan $95 \%$ dan $\alpha 5 \%$.

HASIL

Hasil penelitian didapat bahwa pada kelompok subjek perempuan usia 60-69 tahun, terdapat 81 orang $(77.9 \%)$ dan usia lebih dari 70 tahun, 23 orang (22.1\%). Pada kelompok overweight terdapat 77 orang $(74.0 \%)$ dan obesitas, 27 orang (26.0\%); dimana 90 orang (86.5\%) mengalami osteoporosis dan 14 orang (13.5\%) mengalami osteopenia. Hasil analisis univariat untuk mengidentifikasi karakteristik pasien dapat dilihat pada Tabel.1.

Tabel 2. Distribusi Karakteristik Pasien Perempuan Lansia di Poli Ortopedi Rumah Sakit Umum Al-Fauzan

\begin{tabular}{lcc}
\hline & Frekuensi (n) & Persentase (\%) \\
\hline Usia & & \\
\hline $60-69$ & 81 & 77.9 \\
$>70$ & 23 & 22.1 \\
\hline Indeks Massa Tubuh & & 74 \\
\hline $25-29,9$ (Overweight) & 77 & 26 \\
$30-39,9$ (Obesitas) & 27 & \\
\hline Kekuatan Tulang & & 13.5 \\
\hline Osteopenia & 14 & 86.5 \\
Osteoporosis & 90 & \\
\hline
\end{tabular}


Hubungan antara Kelebihan Berat Badan dengan Kekuatan Tulang Perempuan Lansia

Denina Kusumaningayu Puspitarini, Basuki Supartono, Yuli Suciati

Pada hasil analisis bivariat pada Tabel 2, didapatkan subjek overweight sebanyak 77 orang $(74 \%)$ orang dan obesitas 27 orang (26\%). Subjek overweight 68 orang (88.3\%) menderita osteoporosis, dan osteopenianya sebanyak 9 orang (11.7\%). Sedangkan pada subjek obesitas, terdapat 22 orang (81.5\%) menderita osteoporosis dan osteopenia sebanyak 5 orang (18.5\%).

Tabel 3. Hubungan Kelebihan Berat Badan dengan Kekuatan Tulang Perempuan Lansia di Poli Ortopedi Rumah Sakit Umum Al-Fauzan

\begin{tabular}{|c|c|c|c|c|c|c|c|}
\hline \multirow{2}{*}{ Indeks Massa Tubuh } & \multicolumn{2}{|c|}{ Osteopenia } & \multicolumn{2}{|c|}{ Osteoporosis } & \multicolumn{2}{|c|}{ Total } & \multirow[t]{2}{*}{ P-Value } \\
\hline & $\mathrm{N}$ & $\%$ & $\mathrm{~N}$ & $\%$ & $\mathrm{~N}$ & $\%$ & \\
\hline $\begin{array}{l}\text { Overweight } \\
(25-29,9)\end{array}$ & 9 & $11.7 \%$ & 68 & $88.3 \%$ & 77 & $74.0 \%$ & 0.512 \\
\hline $\begin{array}{l}\text { Obesitas } \\
(30-39,9)\end{array}$ & 5 & $18.5 \%$ & 22 & $81.5 \%$ & 27 & $26.0 \%$ & \\
\hline Total & 14 & $13.5 \%$ & 90 & $86.5 \%$ & 104 & $100 \%$ & \\
\hline
\end{tabular}

Analisis bivariat menggunakan uji Chi-Square, menunjukkan hasil yang tidak bermakna antara kelebihan berat badan dengan kekuatan tulang perempuan lansia dengan nilai P $0.512(p<0.05)$ pada Tabel 2.

\section{PEMBAHASAN}

Berdasarkan hasil penelitian, distribusi responden berdasarkan usia menunjukkan bahwa sebagian besar responden adalah lansia berusia 60-69 tahun, sebanyak 81 orang (77.9\%). Hasil studi ini sesuai dengan penelitian Ramadhani (Ramadhani, 2015) yang menyatakan bahwa proporsi osteoporosis lebih banyak pada kelompok usia 61-70 tahun. Semakin bertambah usia maka akan terjadi peningkatan bone loss, terutama pada lanjut usia (Humaryanto,2019). Usia menopause terkait fungsi estrogen yang menurun akan mengakifkan osteoklas sehingga terjadi osteoporosis (Fitria, 2016).

Distribusi responden perempuan lanisa berdasarkan kekuatan tulang menunjukan bahwa sebagian besar mengalami osteoporosis sebanyak 90 orang (86,5\%). Osteoporsis didahului dengan osteopenia, dimana proses tersebut berlangsung dalam jangka waktu lama yang mengakibatkan penurunan kekuatan tulang (Humaryanto \& Syauqy, 2019). Osteoporosis akibat penuaan terjadi peningkatan adipogenesis sumsum, sehinggga lebih merangsang konversi sel stroma menjadi adiposit daripada osteoblas (Shapses \& Sukumar, 2012).

Hasil penelitian menujukan bahwa pasien overweight (25-29,9) dengan proporsi terbesar sebanyak 68 orang $(88,3 \%)$ mengalami osteoporosis. Serta, pasien obesitas $(30-39,9)$ dengan proporsi terbesar sebanyak 22 orang $(81,5 \%)$ 
ISSN 1978-2071 (Print); ISSN 2580-5967 (Online) Jurnal IImiah Kedokteran Wijaya Kusuma 10(2) : 123-130, September 2021

mengalami osteoporosis. Berdasarkan hasil analisis bivariat menggunakan uji ChiSquare, menunjukkan hasil yang tidak bermakna antara kelebihan berat badan dengan kekuatan tulang perempuan lansia dengan nilai $P 0.512(p<0.05)$.

Penelitian ini sesuai dengan studi Bansal (Bansal \& Bansal, 2017) yaitu, dari 400 subjek penelitian, proporsi terbesar pada pasien overweight dengan osteoporosis. Studi bansal menyatakan berat badan berlebih mungkin tidak dipertimbangkan sebagai faktor pelindung terhadap perkembangan osteoporosis pada wanita (Bansal \& Bansal, 2017). Penelitian ini juga sesuai dengan Greco, bahwa dari 398 subjek yang kelebihan berat badan (BMI 25- 30) tidak menunjukkan modifikasi apa pun dalam kesehatan kerangka (Greco EA, 2011). Studi Greco menjelaskan bahwa obesitas memiliki pengurangan massa mineral tulang dimana terjadi peningkatan produksi proinflamasi sitokin sehingga beresiko keropos tulang (Greco EA, 2011). Studi Paula menjelaskan, kadar lipid yang berlebihan dalam tubuh bersifat toksik (lipotoksisitas) sebagai konsekuensi dari penumpukan lemak di tulang (Paula \& Rosen, C.J., 2015).

Penelitian ini tidak sesuai dengan studi Ristati yang memiliki korelasi positif bahwa semakin tinggi total lemak tubuh (persentase lemak) maka semakin tinggi nilai kepadatan tulang sehingga berpotensi melindungi tulang (Ristati E. W et al., 2017). Studi Ristati menjelaskan efek protektif lemak terhadap kepadatan tulang berupa beban mekanis, jaringan adiposit, dan faktor hormonal (Ristati E. W et al., 2017). Penelitian ini tidak sesuai karena tidak mengukur persentase lemak tubuh.

Penelitian ini juga tidak sesuai dengan Fitria, dimana hubungan IMT dengan densitas mineral tulang pada wanita pascamenopause sangat bermakna (Fitria, 2016). Studi ini menjelaskan osteoporosis pada wanita pasca menopause dengan IMT normal lebih banyak dibanding obesitas, karena hormon estrogen yang dihasilkan oleh jaringan lemak (Fitria, 2016). Penelitian ini tidak sesuai karena subjek hanyak pada lansia dan tidak mencantumkan IMT normal.

Maka dari itu, penelitian ini memiliki keterbatasan diantaranya: (1) Penelitian ini tidak menilai faktor risiko lain yang dapat mempengaruhi kepadatan tulang, (2) Penelitian ini tidak melakukan pemeriksaan lain seperti kadar kalsium darah, vitamin D, dan persentase lemak yang mungkin akan mempengaruhi hasil penelitian; (3) Pengukuran kekuatan tulang ini menggunakan Ultrasound Bone Mineral Densitometry yang keakuratannya lebih rendah dibandingkan DXA (Dual-energy $X$ ray absorptiometry). Studi lebih lanjut 
Hubungan antara Kelebihan Berat Badan dengan Kekuatan Tulang Perempuan Lansia

Denina Kusumaningayu Puspitarini, Basuki Supartono, Yuli Suciati

diharapkan dapat mengevaluasi faktor lain dalam meninjau kekuatan tulang terhadap massa tubuh.

\section{KESIMPULAN}

Dalam penelitian ini dapat disimpulkan bahwa tidak ada hubungan yang bermakna antara kelebihan berat badan dengan kekuatan tulang pada perempuan lanjut usia. Penelitian menunjukkan kelebihan berat badan seperti overweight atau obesitas mungkin tidak dianggap sebagai faktor pelindung terhadap osteoporosis pada perempuan lanjut usia dengan nilai P $0.512(p<0.05)$.

Dari hasil studi, masyarakat perlu memantau indeks massa tubuh yang proporsional dalam menunjang beban tulang. Sehingga modifikasi gaya hidup diperlukan pada lansia mengingat ketidakseimbangan hormonal dan lemak tubuh yang mempengaruhi kepadatan tulang lansia.

\section{UCAPAN TERIMA KASIH}

Penulis mengucapkan terima kasih kepada Direktur Rumah Sakit dr. Prita Kusumaningsih, Sp.OG, serta jajarannya yang telah bersedia membantu persiapan dan pelaksanaan penelitian. Selain itu, penulis juga mengucapkan terima kasih kepada Kepala Pusat Pelayanan Terpadu Lansia, Sumiati dan para kader yang telah membantu dalam melaksanakan proses penelitian. Terima kasih telah membantu penulis dalam menyelesaikan penelitian skripsi ini.

\section{DAFTAR PUSTAKA}

Bansal S, Bansal A, 2017. Relation between Obesity and Osteoporosis in Women. Int J Med Dent Sci. 6 (1): 1382-1385.

Brunetti G, Di Benedetto A \& Mori G, 2014. Bone Remodeling. Imaging of Prosthetic Joints: A Combined Radiological and Clinical Perspective. Springer-Verlag. Italia. 3: 27-37.

Fitria R, 2016. Hubungan Indeks Massa Tubuh, Paritas dan Lama Menopause dengan Densitas Mineral Tulang pada Wanita Pasca Menopause. J Martenity Neonatal. 2 (2): 68-73. Available from: http://e-

journal.upp.ac.id/index.php/akbd /article/view/1075

Greco EA, Fornari R, Rossi F, Santiemma V, Prossomariti G, et al, 2010. Is obesity protective for osteoporosis? Evaluation of bone mineral density in individuals with high body mass index. The International Journal of Clinical Practice. 64 (6): 817-20. 
Humaryanto \& Syauqy, A., 2019. Gambaran Indeks Massa Tubuh dan Densitas Massa Tulang sebagai Faktor Risiko Osteoporosis. Jurnal Kedokteran Brawijaya, 30(3), pp. 218-222.

J Cao, J., 2011. Effects of obesity on bone metabolism. Journal of Orthopaedic Surgery and Research, pp.1-7.

Migliaccio S, Greco EA, Fornari R, Donini LM, Lenzi A, 2011. Is Obesity in Women Protective Against Osteoporosis?. Dove Medical Press Journal: Diabetes, Metab Syndr Obes Targets Ther. 4: 273-82.

Morris-Naumann FL \& Wark JD, 2015. Exercise, Nutrition, and Bone Health. Nutrition and Bone Health $2^{\text {nd }}$ ed. Humana Press, New York. 543-60.

Park S, Na W, Sohn C, 2018. Relationship between Osteosarcopenic Obesity and Dietary Inflammatory Index in Postmenopausal Korean Women: 2009 to 2011 Korea National Health and Nutrition Examination Surveys. J Clin Biochem Nutr. 63 (3): 211-6.

Paula, F.J.A.d. \& Rosen, C.J., 2015. Fat and Bone. In M.F. Holick \& J.W. Nieves, eds. Nutrition and Bone Health. 2nd ed. New York: Humana Press. pp.319-33.

Pusdatin Kementrian Kesehatan Republik Indonesia, 2015. Data \& Kondisi Penyakit Osteoporosis di Indonesia [Internet]. Available from:

https://pusdatin.kemkes.go.id/res ources/download/pusdatin/infod atin/infodatin-osteoporosis.pdf

Pusdatin Kementrian Kesehatan Republik Indonesia, 2016. Situasi Lanjut Usia (Lansia) di Indonesia [Internet]. Available from: https://pusdatin.kemkes.go.id/res ources/download/pusdatin/infod atin/Infodatin-lansia-2016.pdf

Ramadhani, 2015. Hubungan antara Kadar Kalsium Darah dan Tingkat Densitas Tulang pada Pasien Osteoporosis di Rumah Sakit Ibu dan Anak Al-Fauzan Jakarta Periode Januari 2012-Desember 2014. Skripsi. Fakultas Kedokteran Universitas Pembangunan Nasional Veteran Jakarta, Jakarta.

Ristati E. W, L., Kusumastuty, I. \& Putri Arfiani, E., 2017. Hubungan Komposisi Tubuh dengan Kepadatan Tulang. Indonesian Journal of Human Nutrition, pp.2333.

Shapses SA, Sukumar D, 2012. Bone Metabolism in Obesity and Weight 
Hubungan antara Kelebihan Berat Badan dengan Kekuatan Tulang Perempuan Lansia

Denina Kusumaningayu Puspitarini, Basuki Supartono, Yuli Suciati

Loss. Artikel. The Annual Review of

Nutrition. Philadelphia. 32: 287309.

Susan, , Woori , N. \& Cheongmin , S., 2018.

Relationship between

osteosarcopenic obesity and

dietary inflammatory index in

postmenopausal Korean

women:2009-2011. Korean

National Health and Nutrition
Examination Surveys, pp.1-6.

Widyanti LRE, Kusumastuty I, Arfiani EP, 2017. Hubungan Komposisi Tubuh dengan Kepadatan Tulang Wanita Usia Subur di Kota Bandung. Indonesian Journal of Human Nutrition. 1 (1): 23-34. Available from:

kalteng.litbang.pertanian.go.id 